\title{
LABORATORY OBSERVATIONS ON THE VISCIDITY OF MECONIUM
}

\author{
BY \\ JOHN 'L. EMERY \\ From the Department of Pathology, Children's Hospital, Sheffield
}

(RECEIVED FOR PUBLICATION JULY 31, 1953)

\begin{abstract}
Abnormalities in intestinal function associated with changes in meconium, which are usually discussed under the heading of meconium ileus, are responsible for many deaths in the newborn period. Disorders produced by meconium would seem to be largely due to intestinal obstruction due to the meconium being unusually tenacious and firm. The basic constituents of normal meconium have been known for 50 years (Zweifel, 1875; Lewin, 1900) and have recently been the subject of study by Rapoport and Buchanan (1950). We know, however, little of changes in composition of meconium related to the variation in its physical properties. Until more is known our treatment of diseases associated with abnormal meconium is likely to be arbitrary and unsatisfactory.

The present study was undertaken in an attempt to determine some factors related to the tenacity of meconium. The features studied were 'surface tension', water content, tryptic activity and the nitrogen content of dried meconium.
\end{abstract}

\section{Materials and Methods}

The meconium came from a series of necropsies on infants either stillborn or dying a few hours after birth. A further few abnormal specimens were obtained from children dying up to five days after birth from diseases of the intestine.

The consistency of the meconium varied so much that the only satisfactory method of assessing its physical nature appeared to be that of measuring the 'tackiness' of its surface. This was determined by finding the weight necessary to pull a small metal ring, of internal diameter $11.8 \mathrm{~mm}$., made of 0.14 $\mathrm{mm}$. nickle wire, away from the surface of the meconium in a small dish. The principle involved is that of the standard method for the estimation of surface tension by the use of a torsion balance. Since 'surface tension' is a measure of the tendency to contract of the free surface of a liquid and meconium does not appear to be a Newtonian fluid with a free surface, the method used here is not a measure of what is usually termed surface tension. It is rather a measure of the combined adhesiveness and strength of the meconium, i.e. more related to what is termed plasticity or viscosity in a Newtonian fluid. The apparatus used gave a constant reading of $0.56 \mathrm{~g}$. for the surface tension of water. The numbers obtained as weights are of necessity arbitrary and simply of relative value. The method, however, appeared to give remarkably constant readings. Such readings rarely showed a variation of more than $0.02 \mathrm{~g}$.

The water content was obtained by drying a known weight of meconium on a hot plate at $95^{\circ}$ to a constant weight.

The tryptic activity was measured using the simplification of the method of Andersen and Early (1942) previously described (Emery, 1952).

The nitrogen content was estimated on powdered dry meconium using acid digestion and Kjeldahl distillation.

\section{Results}

Variation in 'Surface Tensions'.-The adhesiveness of 64 samples of normal meconium was measured. Four further samples of clinically abnormal meconium of meconium ileus type were also examined. The tension of the normal specimens varied from 0.4 to $3.5 \mathrm{~g}$. More than half of the specimens gave readings between 0.5 and $1.5 \mathrm{~g}$., the numerical distribution suggesting a simple logarithmic incidence. The specimens which were clinically abnormal had greatly increased 'surface tensions', the readings being $14 \cdot 0,22 \cdot 0$, and $5 \cdot 8 \mathrm{~g}$., i.e. showing a range of up to 20 times the average normal. No significant difference was seen in the distribution of readings in the meconium samples taken from the ileum and those taken from the colon.

Variation in Water Content.-The water content was estimated in 56 samples of normal meconium and varied from 70 to $92 \%$ of the total weight. The majority of samples showed a water content of 
between 75 and $85 \%$. These figures are what would be expected to occur in range around the figure of $80 \%$ water given by Feldman (1920) and $72 \cdot 4 \%$ by Rapoport and Buchanan (1950). Five specimens reported by Hymanson and Kahn (1919) had a water content of $73 \cdot 2 \%, 80 \cdot 1 \%, 78 \cdot 4 \%, 69 \cdot 7 \%$ and $71 \cdot 8 \%$.

The water content of three samples of meconium of the meconium ileus type were $62 \cdot 2 \%, 63 \cdot 3 \%$ and $55 \cdot 3 \%$.

Variation in Tryptic Activity.-Tryptic activity was estimated on 48 normal samples and showed a distribution similar to that seen in a previous normal series reported from this laboratory (Emery, 1952).

Variation in Nitrogen Content.-The total nitrogen was estimated in 43 specimens. The levels varied from 4.6 to $15.4 \mathrm{~g}$. \% the majority being between 5 and $7 \mathrm{~g}$. No attempt was made to separate the protein and non-protein nitrogen. The nitrogen content of two of the abnormally tenacious specimens of ileus type only were examined and were 6.95 and $6.18 \mathrm{~g}$. \%, i.e. close to the mean normal level. The specimens with highest nitrogen levels were in all other respects completely normal.

The figures found were considerably higher than that of $2 \cdot 33 \%$ given by Lewin (1900 quoted by Feldman). Von Reuss (1920) considers the nitrogen content of dry residue to be from $2 \cdot 1$ to $5 \%$, Hymanson and Kahn (1919) give the range of total nitrogen of wet meconium as $0.62 \%$ to $1 \cdot 09 \%$ and Trumpp (1912) as $1 \cdot 45 \%$. The present figures are similar to those $(7 \cdot 1,5 \cdot 4,5 \cdot 1,5 \cdot 8,6 \cdot 0$ g. \%) obtained by Rapoport and Buchanan (1950) but the level of $14.4 \mathrm{~g}$. \% suggested as being abnormal by them is within the normal range in the present series.

Relationship between 'Surface Tension' and Water Content.--'Surface tension' and water content were both examined in 56 specimens, and their relationship within the normal range is represented in the target chart in Fig. 1. Of the 27 specimens giving a tension reading of 1 or less, 25 (i.e. $93 \%$ ) had a water content of $80 \%$ or over whereas of the 18 cases having a reading of 1.5 or over, three $(16 \%)$ only had a similar water content.

The specimens from three cases of ileus type all showed a gross diminution in water content.

Excluding the ileus specimens the correlation coefficient between the 'surface tension' and the water content was, $0.670(P<0.001)$ confirming a definite positive relationship of 'surface tension' with dried residue as suggested by the scatter in Fig. 1.

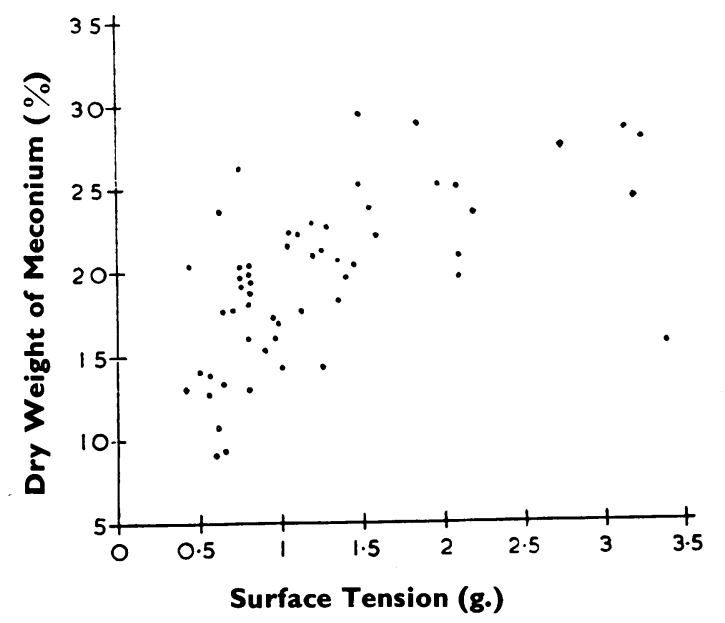

FIG. 1.-The relationship between 'surface tension' and the percentage dry weight of meconium.

Relationship between 'Surface Tension' and Tryptic Activity.-Tension readings and tryptic activity were both estimated on 45 normal specimens. The distribution of their relationship is illustrated in Fig. 2. There appears to be no correlation between the tryptic activity and the surface tension of the specimens of meconium. Of the three specimens of meconium of the meconium ileus type examined, the tryptic activity titre was 1 in 10, 0 and 1 in 40.

Relationship between 'Surface Tension' and Nitrogen Content of Dried Meconium.-Both the adhesiveness and nitrogen content were estimated in 39 normal specimens.

When the specimens were divided on the mean nitrogen content it was found that of 21 specimens

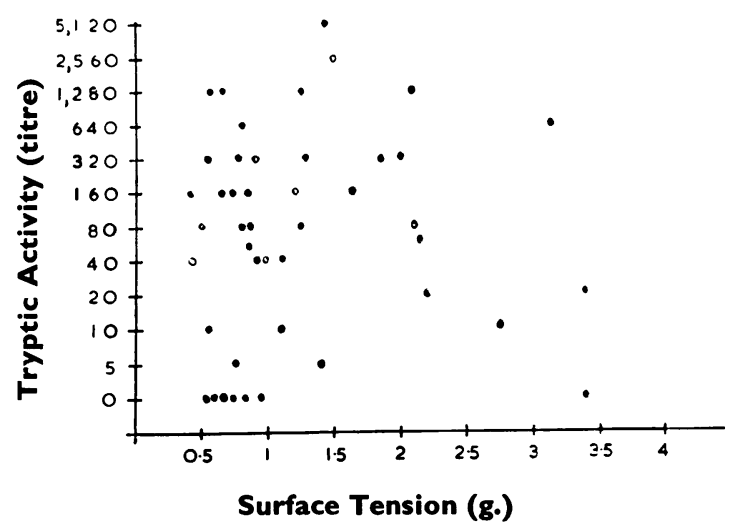

Fig. 2.-The relationship between the 'surface tension' of normal specimens of meconium and the tryptic activity of the specimens. 
having a viscosity of 1 or less, 20 had a nitrogen content of over $6.5 \mathrm{~g}$. \%. In the specimens with 'surface tension' of 1.5 or over, eight of $11(72 \%)$ had a nitrogen content of below $6.5 \mathrm{~g} . \%$.

Examined in another way the correlation coefficient of the 'surface tension' and the logarithm of the nitrogen content gave a value of $0 \cdot 358$, giving a significance of the 0.02 to 0.005 levels. This suggests that there is an inverse relationship between the nitrogen and the tenacity of meconium; i.e. the greater the nitrogen content the more fluid the meconium. It is interesting that the two pathological specimens of meconium with tension readings of $14 \cdot 5$ and 20 had nitrogen levels of $6 \cdot 18$ and $6.95 \mathrm{~g} . \%$ which are very near the mean level for normal meconium.

\section{Discussion}

The most striking observation in this study is the great variation found in all the factors estimated in normal meconium. The question arises whether or not it is legitimate to use meconium obtained at necropsy as being normal meconium. There is, however, little alternative to obtaining meconium in large quantities and uncontaminated by urine than at necropsy or operation. Also children dying within a few hours of birth usually have a cause of death unrelated to the lower alimentary tract, and no difference could be seen between meconium obtained from stillborn children and those dying within a few hours of birth. (It is interesting to note that next to calcified bone meconium is said to be the most durable natural substance of the body (Schmidt, 1897).)

The observation that the tenacity of the meconium bears a direct relationship to the water content of the meconium is not surprising. Gross (1953) in discussing meconium ileus refers to the degree of 'dryness' of the abnormal meconium on purely clinical grounds. From what we know of meconium at the present time it would seem that it consists principally of long-chained molecules of the mucopolysaccharide and muco-protein group. It would seem probable that meconium is not a simple liquid with the muco-protein in solution but a series of 'dispersed systems' (Reiner, 1949) and that the tackiness or viscidity of meconium is determined by the amount of water lying between large molecular masses. In view of the known high rate of fluid transference within the post-natal alimentary tract, it is possible that a minor disturbance in the onset of normal fluid exchange could account for a pathological state of meconium within the bowel.

The value of the negative correlation found between nitrogen content of the dried meconium and its viscidity is difficult to interpret due to our lack of knowledge of the nitrogen linkage within the meconium. But in view of the findings of Rapoport and Buchanan (1950) that a major constituent of meconium is a muco-polysaccharide it seems possible that there is an inverse relation between the quantity of muco-polysaccharide and muco-protein in meconium. Thus the inverse relationship between the nitrogen content and the viscidity may indicate a positive relationship between the viscosity and muco-protein. Rapoport and Buchanan suggested that the enhanced viscosity of meconium in meconium ileus was due to muco-protein being more viscid than muco-polysaccharide and the disease due to an absence of ferments digesting the mucoprotein. The finding in the present study of no correlation between viscidity and the tryptic activity of meconium is difficult to associate with the above hypothesis. It is, of course, not possible to relate the tryptic activity of meconium to the total functional activity of the pancreas, but in all the cases from which meconium was used the pancreas was examined histologically and no changes suggesting fibrocystic disease were found. It seems likely that the tenacity of the meconium within the normal range is not directly related to tryptic secretion of the pancreas. In meconium ileus pancreatic changes are always found by some authors (Bodian, 1952) but cases of meconium ileus having apparently normal pancreatic function have been described (Hinden, 1950). Farber (1944) suggested that different factors might be effective in different cases of meconium ileus. It is quite possible that the pancreatic changes seen so frequently in meconium ileus may not be the primary site of disease.

The specimens of meconium causing obstruction in the present series showed a grossly diminished water content, a normal nitrogen content and a normal or low tryptic activity. The present study suggests that the water content in meconium is a potent factor in determining its viscosity.

\section{Summary}

A series of 64 specimens of normal meconium were examined for 'surface tension', water content, nitrogen and tryptic activity. Extremely wide ranges were found in all factors. The viscidity of the meconium is directly related to the water content. It appears to be inversely related to the nitrogen content, and unrelated to the tryptic activity of meconium. Specimens from four cases of meconium obstruction showed a greatly diminished water content, normal nitrogen and normal or low tryptic activity. 
It is a pleasure to acknowledge the help of Miss $\mathrm{C}$. Roseman, Statistician to the University of Sheffield. for the help in statistical analysis, and to Mr. H. R, Norman, B.Sc., who carried out the nitrogen estimations.

\section{REFERENCES}

Andersen, D. H. and Early, H. V. (1942). Amer. J. Dis. Child., 63, 891. Bodian, M. (1952). Fibrocystic Disease of the Pancreas, p. 86. London. Emery, J. L. (1952). Archives of Disease in Childhood, 27, 67.

Farber, S. (1944). J. Pediat., 24, 387.
Feldman, W. M. (1920). The Principles of Ante-Natal and Post-Natal Child Physiology, p. 191. London.

Gross, R. E. (1953). The Surgery of Infancy and Childhood, p. 181. Philadelphia.

Hinden, E. (1950). Archives of Disease in Childhood, 25, 99

Hymanson, A. and Kahn, M. (1919). Amer. J. Dis. Child., 17, 112. Lewin, - - (1900). Inaug. Dissert St. Petersburg: (quoted by Feldman). Rapoport, S. and Buchanan, D. J. (1950). Science, 112, 150. Reiner, M. (1949). Deformation and Flow, pp. 53-69. London

Reuss, A. R., Von (1920). The Diseases of the Newborn, p. 36. London. Schmidt, F. C. T. (1897). Vjschr. Gerichtl. Med., ser. 3, 13, 320. Trumpp, J. (1912). Jb. Kinderheilk., 76, 678.

Zweifel, - -. (1875). Arch. f. Gynäk., 7, 474 (quoted by Feldman). 